\title{
Behavioral Intervention Teams Using Threat Assessment
}

\author{
Daniel D. Graney, Ed.D. \\ University of Rhode Island \\ Johnson \& Wales University
}

\begin{abstract}
This descriptive-exploratory study investigated behavioral intervention teams at state flagship universities in New England $(N=6)$. Using a mixed methods approach, this study investigated whether there were significant differences between the behavioral intervention teams in terms of team leadership and composition, operational practices and training, and responsibilities related to threat assessment. Behavioral assessment team leaders $(N=6)$ and team members $(N=28)$ were surveyed to determine if there is a relationship between levels of training and the functional implementation of threat assessment. Team leaders $(N=6)$ and executive administrators $(N=4)$, who were responsible for oversight of the behavioral intervention teams, were interviewed to gather additional information about team formation, processes, and long-term strategic planning around institutional threat assessment systems. The findings showed that although each team was unique, there were no significant differences in terms of the research variables. However, there was a significant positive correlation between level of training and confidence in using threat assessment techniques among team members. Team variations allowed for a number of recommendations to be made based on the findings and on expert opinions available from the literature.
\end{abstract}

\section{Author Note}

Daniel D. Graney, Ed.D., Office of Student Life, University of Rhode Island.

This research was originally published as part of a doctoral dissertation completed in May 2011 at the School of Education at Johnson \& Wales University.

Correspondence concerning this article should be addressed to Daniel D. Graney, Office of

Student Life, University of Rhode Island, 302 Memorial Union, Kingston, RI 02881.

E-mail: dgraney@uri.edu 


\section{Introduction}

Incidents of violence on college campuses, although rare, are devastating. In response to recent shootings, many colleges and universities have followed the best practice recommendations of the U.S. Department of Education (2006) and formed multidisciplinary behavioral intervention teams that address potential violence on campus (Delworth, 1989; Vossekuil, Fein, Reddy, Borum, \& Modzeleski, 2002). One preventative approach often, but not always, employed by these teams is threat assessment. Threat assessment has been defined as "a set of operational activities that combine the use of an investigative process and information-gathering strategies to inform a set of relevant questions, which are used to determine whether a student/situation poses a serious risk of targeted violence" (Randazzo, Borum, Vossekuil, Fein, Modzeleski, \& Pollack, 2006, p. 151).

In a school or college/university setting, the threat assessment approach endorsed by the U.S. Department of Education requires "the person or team conducting the inquiry to gather information, and answer key questions about the case, and to evaluate the evidence suggesting movement toward violent action" (Randazzo, et al., 2006, p. 153). Behavioral intervention teams are often charged with addressing crises, disturbing behavior, and medical and psychiatric situations of individual students, faculty, and or staff. Behavioral intervention teams often conduct threat assessments and should be the primary investigators of whether a student has the intent and the means to carry out the threat. Additionally the teams "will also take actions to help the student resolve the problem or conflict that stimulated the threat" (Cornell, 2008, p. 11).

Having a multi-disciplinary behavioral intervention team that uses the threat assessment approach is the most cited best practice supported by the U.S. Department of Education and federal law enforcement agencies. However, there is very little research on how to effectively implement threat assessment on campuses.

\section{Behavioral Intervention and Threat Assessment Teams}

There are a number of similarities between the definition of a behavioral intervention team and a threat assessment team. In the literature the two terms are often used interchangeably. However, the primary difference is that threat assessment teams are designed to be smaller, more responsive, and focused on student or staff concerns that have escalated into threatening situations.

Conversely, a behavioral intervention team is designed to deal with any concerning behaviors that have come to its attention, with the intention of assisting the student or staff person in accessing the necessary resources. In the process of completing an assessment, behavioral intervention teams may be called upon to investigate and assess threatening or concerning behavior. This study from 2011 investigated how behavioral intervention teams use the threat assessment approach in their work. 


\section{Methodology}

\section{Research Design}

This study was designed to use a twophased, mixed-methods, descriptiveexploratory study of the behavioral assessment team at the flagship universities in New England. The data for the study were comprised of questionnaire results, interview results, and the collection and review of online documentation from multiple sites. Information from the three sources was triangulated.

\section{Participants}

The participants for this study were the behavioral assessment team members and executive administrators responsible for team oversight at the state flagship universities in New England $(N=6)$ : University of Connecticut; University of Maine; University of Massachusetts, University of New Hampshire; University of Rhode Island; and, University of Vermont.

For the first phase, those administrators identified as the team leaders $(N=6)$ and executive administrators with oversight responsibility for teams $(N=4)$ were interviewed. For the second phase, identified members of behavioral intervention teams $(N=44)$ and the team leaders at each university were asked to complete the questionnaire. The questionnaire response rates were $100 \%$ for the team leaders ( 6 responses $/ 6$ leaders) and $64 \%$ for the team members (28 responses/44 members).

\section{Instruments}

The first-phase interviews were semistructured in nature, as flexibility was needed to lead the conversation to areas or topics that were more relevant for one institution than another. These interviews addressed the three functions of threat assessment: identification, assessment, and management (Fein, Vossekuil, Pollack, Borum, Modzeleski, and Reddy, 2002). The interviews also inquired about any policies, procedures, strategic planning, and systemwide incorporation of crisis prevention efforts and training.

There were two survey instruments developed for phase two of this study. The first questionnaire was sent to the team leaders at each institution to gather data on the teams' composition, responsibilities, and practices in using threat assessment. The second questionnaire was designed for the behavioral assessment team members. Responses were measured using a 5-point Likert-type scale.

\section{Data Collection}

Contact was made with the student affairs administrators at the flagship universities to identify the team leaders of the behavioral intervention teams. Team leaders were contacted by e-mail, describing the study and requesting their assistance. The interviews were digitally recorded in order to ensure the accuracy of the responses.

Following the interviews, the team leaders were provided a link to the online team leader survey. Team leaders were also asked to provide their team members with 
a link, via e-mail, to the online team member questionnaire and to encourage their participation.

\section{Data Analysis}

Data analysis for the interview results included a "cross-case analysis, which means grouping together answers from different people to common questions for analyzing different perspectives on central issues" (Patton, 1990, p. 376). This allowed for comparison of similarities and differences across institutions.

The questionnaire data were analyzed using descriptive statistics including frequencies, means, and standard deviations. Team data were compared for group differences using one-way analysis of variance (ANOVA). Correlation analysis was used to address data for comparison regarding questions around training and self-efficacy with threat assessment.

\section{Results}

The data collected from the interviews with the six behavioral assessment team leaders and four executive administrators resulted in a number of relevant themes. The data from the questionnaire, completed by the team leaders and team members, were analyzed with reference to the primary and secondary research questions.

The data from each university were aggregated and analyzed as a whole. The universities are identified by randomly assigned numbers, rather than alphabetic or other identifiable order. To protect the identity of the institutions, responses were not analyzed for individual universities, except to report the questionnaire return rates.

The response rate for the team leader questionnaire $(N=6)$ was $100 \%$. The response rates for the team members at each institution varied:

- University $1(N=5)=71 \%$

- University $2(N=3)=60 \%$

- University $3(N=4)=67 \%$

- University $4(N=4)=57 \%$

- University $5(N=3)=33 \%$

- University $6(N=9)=90 \%$

$$
\text { Total }(N=28)=64 \%
$$

The small number of team leaders $(N=6)$ and team members $(N=28)$ limited the number and type of statistical analyses performed on the data.

\section{Virginia Tech as the Common Theme}

The over-riding theme common to all of the interviews conducted was the significance of the shootings at Virginia Polytechnic Institute and State University (Virginia Tech) on Monday, April 16, 2007 (Virginia Tech Review Panel, 2007). All of the team leaders and executive administrators agreed that prior to the shootings at Virginia Tech there was some type of informal group that met on their campus to discuss students or events that raised concerns. What followed after April 2007 was a major push at all of the studied universities to formalize previously unofficial practices and make these efforts more transparent. This catalyst for change was matched to an equal degree by the shootings at Northern Illinois University 10 months later (Cable News Network, 2008). This incident was 
equally significant because it showed that the massacre at Virginia Tech was not an isolated incident and that this would be a problem that colleges and universities would have to continually address.

\section{Interview and Survey Results}

The differences between behavioral intervention teams were investigated by examining the composition, practices, and responsibilities as they relate to threat assessment for each of the six flagship universities. The variables in this study were investigated based on the principles of effective drug-abuse, delinquency, and youth-violence prevention programs examined by Nation et.al in 2003 (Nation, Crusto, Wandersman, Kumpfer, Seybolt, Morrissey-Kane, \& Davino, 2003). The variable of team composition was measured by examining how comprehensive the team was in regards to having membership from key areas of the campus, and how collaboratively the team members communicated with and interacted within the team itself and with those in other campus areas (Nation et al., 2003).

The second variable, team practices, was measured by investigating whether the teams used varied methods, in terms of investigations, information gathering and reporting, and educating and encouraging reporting by the campus community. Practices were also measured by examining how comprehensive the informationgathering efforts used by the team appeared to be and whether the interventions were appropriately timed; that is, did the team have the capacity to intervene quickly enough to have an impact on developing situations. Another investigated element of practice was to determine whether these practices were driven by the principles of the threat assessment approach as described by Deisinger, Randazzo, O'Neill, \& Savage (2008).

The third variable of team responsibilities was measured by investigating whether interventions are sustained over time; if there was an effort to continually evaluate and improve the effectiveness of the team; and if the team members engaged in regular, basic, or advanced training in threat assessment.

Composition. The five major themes, developed from the team leader and executive administrator interviews that spoke directly to the issue of team composition were leadership, making the call, team model, and team membership based on size and functional area within student affairs.

1. Leadership -Several leadership models for the team were identified and ranged from having a senior student affairs officer leader to having no named leader.

2. Making the call -Teams varied in terms of whether the team made the final determination of a threat or if the team leader made the decision after receiving feedback from the team.

3. Team model -Three different team models were identified that were based on the various configurations used by the studied universities. 
4. Size and functional area -Teams also varied in size; however, every team leader reported that team membership was based on functional area not on personalities.

5. Increased communication - Teams were credited with breaking down traditional communication barriers and intrinsically fostering increased communication between different areas on campus.

Practices. Under the variable of team practices, seven main themes were identified.

1. Reporting methods - Many teams rely on telephone, e-mail, or walk-in reporting methods. However, one team has a functional online reporting mechanism and two other teams have an online reporting option in development.

2. Individualized responses -One of the most consistent themes was the importance of the team addressing each situation on a case-by-case basis and offering individualized interventions.

3. Campus radar -Team members frequently act as the campus radar system; that is, they continually scan the environment and, when they become aware of a particular situation that spans multiple areas, they give attention to that situation.

4. Responsiveness - The importance of team responsiveness, namely being able to react in sufficient time to intervene in an escalating situation was stressed.

5. Assessing behavior -All teams agreed that their assessments are based on observed behavior and not profiles, hearsay, or other suppositions.

6. Threat rating scale -Only one team reported using a threat rating scale in assessment of concerning behavior. Others reported being reluctant to categorize a situation that might cause quick escalation to a dire situation.

7. Data collection - Teams varied on the amount of and purposes for data collection. Some used data for case management purposes only, while others collect as much data as possible in the hopes of identifying trends to guide strategic planning.

Responsibilities. Assessing the principles of having a well-trained staff, outcome evaluation, and institutional support measured the research variable of responsibilities.

Training -Most training focused on the campus community and not on team members. Although there were some reported instances of specific team member training, most focused on the teams' efforts to train others in the campus community on how, where, and when to report concerning situations.

Outreach -All but one team reported spending considerable time and resources on outreach to the campus community to inform various groups about the team and to explain the reporting guidelines.

Student retention -Another common theme was the importance of student retention as a goal for the team. The focus of all the teams is to help students who are in crisis reach the resources they need in order 
to continue with their education, and with as little interruption as possible.

\section{Team Leader and Team Member Questionnaire Findings}

Descriptive statistics, frequencies, ranked means, and standard deviations, were used to measure the items related to the variables of composition, practices and responsibilities. The results from the Team Member Questionnaire ANOVA suggest that the behavioral intervention teams at the flagship universities are different in regards to having clearly stated goals and/or a clear mission statement. Specifically, these results indicate that the team members of University 6 show the team was lacking in either clearly stated goals or a clear mission statement, whereas Universities 1 and 3 both had very high agreement among their respective team members that their teams had clearly stated goals and/or a clear mission statement. (See Appendix A, Table A2.) There were no significant differences among the teams for any of the other measured variables. The only other result worth note is the strong positive correlation between the team members' level of selfconfidence with threat assessment and the level of training they had received. (See Appendix A, Table A3.)

\section{Analysis of Web-Based Team Information}

As a third point of data collection, an Internet search of the six universities was conducted. Analysis of the web-based information of each university was considered important because it gives an indication of how easy it is to find information and resources. The complete findings can be seen in Appendix A, Table A4.

\section{Discussion}

One of the key assumptions underlying the study was the understanding that every university is different, with different challenges, cultures, students, and resources. Acknowledging this fact provides the rationale for why every university will not, and should not, have the same type of behavioral assessment team. In fact, the studied universities use completely different team structures in terms of leadership, model, and membership for the behavioral intervention teams. However, the findings show that although all six teams are different, they are not significantly different in terms of their composition, practices, and responsibilities. These findings, and the literature, suggest that there are some key areas that all universities should consider when developing their behavioral intervention teams.

\section{Leadership}

One key study finding was the importance of the behavioral assessment team leadership. The studied teams varied greatly in terms of their leadership models. Although they employed different models, all but one of the teams had an identified leader or co-leaders. The study findings suggest that there is not one leadership model that would work for every university. But given the suggestions in the literature and from this study, the co-leader model emerged as one worthy of consideration with both a senior student affairs administrator and the chief of the campus 
police force leading the team. One benefit of this model is that, unlike mental health professionals, neither senior student affairs administrators nor campus police are "limited by medical confidentiality laws and, therefore, often have greater flexibility in sharing student information on a need-toknow basis" (Dunkle, Silverstein, \& Warner, 2008, p. 593).

\section{Team Member Selection}

There are many different theories and models in the literature about how to select members of a behavioral assessment team, but it really comes down to the needs of the particular institution. "Critical to successful team operation is selection of team members, which depends on the mission of the team and specifics of the community" (Eells \& Rockland-Miller, 2011, p. 15). The study findings and relevant literature are in agreement that team members should initially be selected based on their functional area within the university. Many of the studied teams were composed mostly of student affairs personnel. That is to be expected, given that they represent areas that are likely to have the most student contact. However, it is important to consider including representatives from other touch points on campus where decisions with consequences are made or areas with high student traffic (Deisinger et al., 2008). It is recommended that team leaders ensure that not only are all of the usual suspects at the table, but that they are able to think outside the box. This research suggests that institutions should consider having people serve on the team who may have access to vital information or resources that could be useful to the team, regardless of whether they are in a different division.

\section{Clear Goals and Mission}

The only significant difference among the studied teams was the issue of having clear goals and a mission statement available to the campus community. It is important that the mission statement and the strategic plan reflect the nature of the team's work. If one of the primary goals of the team is student retention, as noted in the interviews, then that should be indicated in the goals and mission statement. It is important to review the goals and mission of the team annually, as the purpose of these items is to "serve as a guide for the teams' overall operations, and to serve as a reminder of the team's purpose when it gets caught up in day-to-day minutiae" (Deisinger et al., 2008, p. 26).

\section{Training}

One of the key study findings was the positive correlation between level of training and team members' confidence in using the threat assessment approach. However, there was some disagreement about which members of the team need to be trained. Some of the studied teams make an effort to train each member on threat assessment; others rely on their law enforcement or counseling services for the actual threat assessment, while the rest of the team was relegated to information gathering and area expertise.

Based on the findings, the researcher feels that although team members should work from their own area of expertise, it is recommended that they all receive training on the threat assessment approach. The reasons for this recommendation are simple-the more people who are trained, the more likely they are to recognize 
situations that have the potential to escalate toward violence. The more familiar team members are with the process, the greater understanding they will have with what they are trying to achieve as a team.

Training in threat assessment should be comprehensive, ongoing, and provided by an expert in the field (Deisinger et al., 2008; Deisinger, Pollard \& Randazzo, 2011; Randazzo \& Plummer, 2009). Comprehensive training covers the basics of threat assessment, including how to identify, assess, and manage persons or situations that raise concern. These situations could include threats of violence or self-harm and other significantly disturbing or disruptive behavior. These trainings should be delivered from an expert in the field of threat assessment (Randazzo, personal communication, January 21, 2011).

In conclusion, this study explored the differences between behavioral intervention teams and their use of the threat assessment approach at flagship universities in New England. Violence on college campuses has been considered one of the leading issues facing institutions of higher education, both in the United States and around the world.

The findings of this study will provide university leaders with information that can be used to make campus behavioral intervention teams more effective in their use of threat assessment techniques. By gaining a better understanding of what threat assessment is and how to employ threat assessment techniques on campuses, university leaders can make great strides in keeping students and campus communities safer for everyone.

\section{References}

Cable News Network. (2008, February 14). 5 shot dead, including gunman, at Northern Illinois University. CNN U.S. Retrieved from http://www.cnn.com/2008/US/02/14/u niversity.shooting/index.html?iref=allse arch

Cornell, D. (2008). Threat assessment on the college campus. Leadership Exchange, 5(4), 8-14. Retrieved from http://www.leadershipexchangedigital.com/leadershipexchange/2008wi nter/\#pg1

Cornell, D., Sheras, P., Gregory, A., \& Fan, X. (2009). A retrospective study of school safety conditions in high schools using the Virginia threat assessment guidelines versus alternative approaches. School Psychology Quarterly, 24, 119-129.

Deisinger, G., Pollard, J., \& Randazzo, M. (2011). Threat assessment q \& a: "Should counseling center staff conduct 'direct threat' or 'fitness for duty' evaluations?" [Web log post]. Retrieved from

http://threatmanagement.blogspot.com /2011/03/threat-assessment-q-shouldcounseling.html

Deisinger, G., Randazzo, M., O'Neill, D., \& Savage, J. (2008). The handbook for campus threat assessment and management teams. Massachusetts: Applied Risk Management. 
Delworth, U. (1989). The AISP model: Assessment-intervention of student problems. In U. Delworth (Ed.), Dealing with the behavioral and psychological problems of students; New directions for student services (pp. 11-21). San Francisco, CA: Jossey-Bass.

Dunkle, J. H., Silverstein, Z. B., \& Warner, S. L. (2008). Managing violent and other troubling students: The role of threat assessment teams on campus. Journal of College and University Law, 34(3), 585-636.

Eells, G. T., \& Rockland-Miller, H. S. (2011). Assessing and responding to disturbed and disturbing students: Understanding the role of administrative team in institutions of higher education. Journal of College Student Psychotherapy, 25, 823. doi:10.1080/87568225.2011.532470

Fein, R., Vossekuil, B., Pollack, W., Borum, R., Modzeleski, W., \& Reddy, M. (2002). Threat assessment in schools: A guide to managing threatening situations and to creating safe school climates. [U.S. Secret Service, National Threat Assessment Center website]. Retrieved from

http://www.secretservice.gov/ntac.sht $\mathrm{ml}$

Nation, M., Crusto, C., Wandersman, A., Kumpfer, K. L., Seybolt, D., MorrisseyKane, E., \& Davino, K. (2003). What works in prevention: Principle of effective prevention programs. The American Psychologist, 58(6-7), 449456.
Patton, M. Q. (1990). Qualitative evaluation and research methods $\left(2^{\text {nd }} e d.\right)$. Newbury Park, California: SAGE Publications.

Randazzo, M. R., Borum, R., Vossekuil, B., Fein, R., Modzeleski, W., \& Pollack, W. (2006). Threat assessment in schools: Empirical support and comparison with other approaches. In J. Jimerson \& $\mathrm{M}$. Furlong (Eds.), The handbook of school violence and school safety: From research to practice (pp. 147-156). Retrieved from http://campusthreatassessment.org/ind ex.php/public_resources/

Randazzo, M. R., \& Plummer, E. (2009). Implementing behavioral threat assessment on campus: A Virginia Tech demonstration project. Blacksburg, VA: Virginia Polytechnic Institute and State University. Retrieved from http://www.sigmatma.com/books.html

Randazzo, M. R., \& Deisinger, G. (2010, December 2). How to find a good threat assessment consultant: 5 questions to ask before you hire [Web log post]. Retrieved from http://threatmanagement.blogspot.com /search?updated-min=2010-0101T00\%3A00\%3A0005\%3A00\&updated-max $=2011-01-$ 01T00\%3A00\%3A00-05\%3A00\&maxresults $=5$ 
U.S. Department of Education. (2006). Creating emergency management plans. ERCM Express. 2(8),1-12. Retrieved from the Readiness and Emergency Management for Schools Technical Assistance Center website: http://rems.ed.gov/docs/CreatingPlans. pdf

Virginia Tech Review Panel. (2007). Mass shootings at Virginia Tech: Report of the review panel presented to Governor Kaine, Commonwealth of Virginia. [Virginia Tech website]. Retrieved from http://www.threatassessment.vt.edu/res ources/tat_info/index.html

Vossekuil, B., Fein, R., Reddy, M., Borum, R., \& Modzeleski, W. (2002). The final report and findings of the safe school initiative: Implications for the prevention of school attacks in the United States. [U.S. Secret Service, National Threat Assessment Center website ]. Retrieved from http://www.secretservice.gov/ntac_ssi.s html 


\section{Appendix A \\ Study Findings \& Statistical Tables}

Table A1

Team Member Areas Identified by Team Leader Questionnaire $(N=6)$

Area Represented

Housing \& Residential Life

Student Life / Dean of Students

Mental Health Consultant / Counseling Center

Police / Campus Security

Student Conduct

Specialty Members (determined on case by case basis)
Percent

100

100

$100 \quad$ Highest

83

83

83
Faculty

Human Resources

Other "Eyes and Ears" offices

Administration (Vice President level or above)

Academic Affairs / Provost

Legal Counsel

Graduate / Professional Schools

Other Touch Points
33

33

33

17 Mid Range

17

17

17

17

Faculty from multiple colleges / departments

Faculty Senate 0

Media Relations

0

International Student Office

Lowest

0 


\section{Table A2}

Comparisons of Team Composition, Practices, and Responsibilities From Team Member Questionnaires ( $N=29)$

\begin{tabular}{|c|c|c|c|c|c|c|c|c|c|c|c|c|c|c|}
\hline \multirow[t]{3}{*}{ Research Variable } & \multicolumn{14}{|c|}{ University } \\
\hline & \multicolumn{2}{|c|}{1} & \multicolumn{2}{|c|}{2} & \multicolumn{2}{|c|}{3} & \multicolumn{2}{|c|}{4} & \multicolumn{2}{|r|}{5} & \multicolumn{2}{|r|}{6} & \multirow[b]{2}{*}{$F$} & \multirow[b]{2}{*}{$p$} \\
\hline & $M$ & $S D$ & $M$ & $S D$ & $M$ & $S D$ & $M$ & $S D$ & $\bar{M}$ & $S D$ & $\bar{M}$ & $\overline{S D}$ & & \\
\hline COMPOSITION & & & & & & & & & & & & & & \\
\hline 4. Adequate representation. & 4.33 & 1.21 & 4.67 & .58 & 4.75 & .50 & 4.25 & .50 & 4.33 & .58 & 3.89 & .31 & .738 & .602 \\
\hline $\begin{array}{l}\text { 5. Unrepresented areas are } \\
\text { monitored effectively. }\end{array}$ & 3.67 & .52 & 3.67 & 1.53 & 4.25 & .50 & 3.00 & .82 & 4.00 & 1.00 & 2.78 & .67 & 2.81 & .040 \\
\hline $\begin{array}{l}\text { 20. Reports are corroborated } \\
\text { from additional sources. }\end{array}$ & 4.33 & .52 & 4.00 & .00 & 4.75 & .50 & 4.50 & .58 & 4.33 & .58 & 3.67 & .71 & 2.60 & .052 \\
\hline $\begin{array}{l}\text { 21. Effectively uses systems } \\
\text { in place on campus. }\end{array}$ & 4.00 & .89 & 4.67 & .58 & 4.75 & .50 & 4.50 & .58 & 4.00 & .00 & 4.00 & .50 & 1.58 & .205 \\
\hline $\begin{array}{l}\text { Practices } \\
\text { 8. Capacity to investigate } \\
\text { quickly to have impact. }\end{array}$ & 4.00 & .63 & 4.33 & .58 & 4.75 & .50 & 4.25 & .96 & 4.33 & .58 & 3.22 & .97 & .411 & .836 \\
\hline $\begin{array}{l}\text { 16. Encourages reporting } \\
\text { and offer multiple ways. }\end{array}$ & 3.67 & 1.03 & 4.33 & .58 & 4.75 & .50 & 4.25 & .50 & 3.33 & 1.15 & 3.33 & 1.12 & .835 & .538 \\
\hline $\begin{array}{l}\text { 17. Capacity to offer } \\
\text { multiple interventions. }\end{array}$ & 2.83 & 1.33 & 4.00 & .00 & 4.50 & .58 & 3.75 & .96 & 3.33 & 1.15 & 3.11 & .60 & 2.29 & .079 \\
\hline
\end{tabular}




\section{Table A2}

Comparisons of Team Composition, Practices, and Responsibilities From Team Member Questionnaires $(N=29)$ (continued)

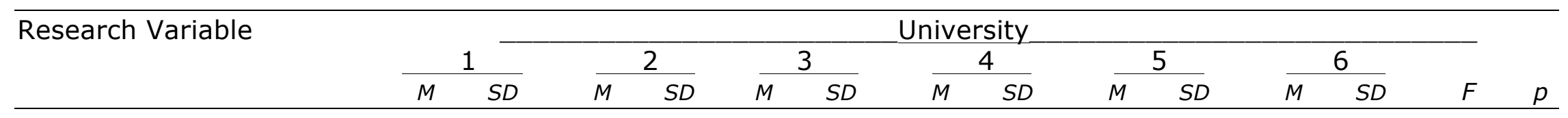

\section{Responsibilities}

1. Received basic training

in threat assessment.

$\begin{array}{lll}4.17 \quad .41 \quad 4.33 & .58\end{array}$

$4.33 \quad .58$

$\begin{array}{llll}3.67 \quad 1.32 & .411 \quad .836\end{array}$

2. Enough training to use threat assessment.

$\begin{array}{llll}4.17 & .41 & 4.67 & .58\end{array}$

$3.75 \quad 1.26$

$3.75 \quad .50$

$4.33 \quad .58$

$\begin{array}{llll}3.56 & 1.33 & .835 & .538\end{array}$

3. Satisfied with level of formal training.

$3.50 \quad .84$

$4.00 \quad .00$

$3.50 \quad 1.29$

$3.00 \quad 1.15$

4.00

.00

3.33

$1.58 \quad .388 \quad .852$

6. Effectively monitors

beyond initial threat.

$3.83 \quad .41 \quad 4.00 \quad .00$

$4.50 \quad .58$

4.25

4.33

.58

3.67

$\begin{array}{lll}.71 & 1.37 & .273\end{array}$

7. Clearly states goals and/or

mission statement

4.17

$\begin{array}{llll}4.33 & .58 & \mathbf{4 . 5 0} & .58\end{array}$

$3.75 \quad 1.26$

4.00

1.00

2.44

$.88 \quad 5.75 .001 *$

*Using the Bonferroni adjustment required significance at the $\mathrm{p}<.012$ for Composition, $\mathrm{p}<.01$ for Practices, and $\mathrm{p}<.017$ for Responsibilities; For item $7(p=.001)$ the effect size is .56 ; Effect size guidelines indicate $.01=$ small; $.09=$ medium; $.14=1$ arge.

Note. The response format is as follows: $1=$ strongly disagree, 2 = disagree, $3=$ undecided, $4=$ agree, $5=$ strongly agree. 
Table A3

Correlations Between Level of Training and Level of Self-Confidence in Using Threat Assessment From Team Member Questionnaire $(N=29)$

Level of Training

Level of Self-Confidence

9. Confident in overall ability to investigate threats.

11. Confident in ability to discern when someone poses a serious threat to themselves or others

$$
\begin{aligned}
& \begin{array}{c}
r \\
.61
\end{array} \\
& \text { (.001) }
\end{aligned}
$$

2) Enough Training

3) Satisfaction With Training

$$
\frac{r}{.46}
$$

$$
\frac{r^{2}}{.21}
$$$$
\frac{r}{.15} \quad \frac{r^{2}}{.02}
$$$$
(.431)
$$

\footnotetext{
a Significant levels are listen in parenthesis.

${ }^{\mathrm{b}}$ Effect size guidelines $r^{2}$ : small $=.01$, medium $=.09$, and large $=.25$
} 
Table A4

Web-based Search Results for Team Information on University Websites

Key Word / Team Specific

$$
\text { University }
$$

Search Parameters

\begin{tabular}{lllllll}
\hline 1 & 2 & 3 & -4 & 5 & 6
\end{tabular}

\section{Key Word}

1) Behavioral Assessment

2) Threat Assessment

3) Disruptive/ Threatening

Student Behaviors

4) Student Concerns

Team Specific Parameters
5) Team Name
6) Mission/Charge
7) Operating Goals/Guidelines
8) Contact Information
9) Online Reporting Mechanism
10) Team Members
11) Term Definitions

$\begin{array}{ll}x & x \\ x & x \\ x & x\end{array}$

$\mathrm{X}$

$\mathrm{X}$

$x$

$x$

$\mathrm{X}$

$\begin{array}{llll}x & x & x\end{array}$

$x \quad x \quad x$

$\mathrm{X} \quad \mathrm{X}$

$x \quad x \quad x$

$\mathrm{X}$

X $\quad x$

$\begin{array}{llll}X & X & X & X\end{array}$

